\title{
Changing domains in human capital measurement
}

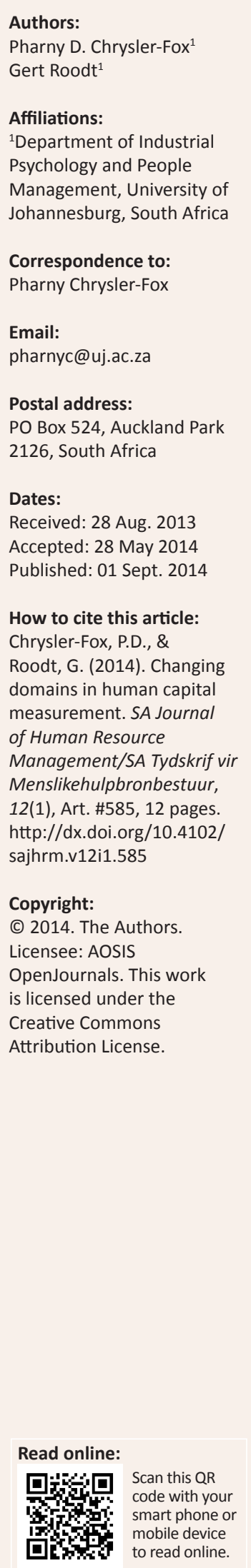

Orientation: The management context is dynamic; this is especially evident in human capital as the primary source of value creation as opposed to physical and natural resources. In response, measurement methodologies have moved from a transactional approach (strategy implementation) to a transformational approach (human capital contribution paradigm), as well as diverging into different purposes. To date, there has been little overlap on recent domains to consider in managing and measuring the contribution of the human resource function and employees, and how to unlock and add value.

Research purpose: The aim of the study was to explore and describe changing domains within human capital management to be managed and measured.

Motivation for the study: The motivation was to advance the understanding of changing measurement domains to aid practitioners to manage and measure the contribution of the human resource function and employees, in order to unlock and add value and ultimately contribute to the success of an organisation.

Research design, approach and method: Unstructured, in-depth interview data of purposively selected cases from a selected panel of human resource practitioners specialising in human capital measurement was thematically analysed in this exploratory-descriptive investigation.

Main findings: Findings suggested that seven domains should be managed and measured. These domains highlight new areas of impact and levels of management. In addition, crossdomain relationships in measurement allow for an understanding of the impact and potential value on which to capitalise.

Practical/managerial implications: New domains to manage and measure focus the attention of practitioners beyond the transactional performance management paradigm to a transformational approach to influence the business strategy. Higher education institutions need to develop students' cognitive skills to facilitate systems thinking.

Contribution: This study suggests a new approach to managing and measuring the human capital function and the workforce.

\section{Introduction}

Measurement frameworks for the measurement of human resource (HR) and human capital are in transition. (For clarity, the term human capital is employed where HR denotes management practices to manage human capital, the latter signifying a collective of unique attributes of employees or the workforce.) This transition is due to the fact that contemporary frameworks have different purposes and no longer reflect the Balanced Scorecard's (Kaplan \& Norton, 1996) perspectives and subsequent developments. These transitions echo Becker, Huselid and Ulrich's (2001) observation 12 years ago that:

there is little consensus, ... and no real framework for thinking about the subject ... [and] we have seen little improvement in this over this over the past eight years. (p. ix)

This study explores the changing human capital measurement domains.

The awareness of human capital and its measurement practices have diverged, despite Becker et al.'s (2001) observation that they have all converged. This is clear in the different purposes of frameworks, which are mainly driven by advancement in measurement. Rooted in the performance management paradigm, with the main (and transactional) aim of implementing the business strategy, we observe various scorecards (see Becker et al., 2001 and Huselid, Becker \& Beatty, 2005, for discussion of the HR Scorecard and the Workforce Scorecard). Not all scorecards in the literature are complementary (see Phillips, 2005, for examples of transactional scorecards applicable to human resource management). The complementary scorecards paved 
the way towards the transformational approach embedded in a human capital contribution paradigm. Different strands in this paradigm aim to show the impact of people and people-related initiatives on the bottom line (e.g. Bassi \& McMurrer, 2008; Boudreau \& Ramstad, 2007; Cantrell, Benton, Laudal \& Thomas, 2006) and on the financial value of human capital (people as assets) (e.g. Scholz, Stein \& Müller, 2007). This is in acknowledgement of human capital as the primary source of value creation as opposed to physical and natural resources (Bassi \& McMurrer, 2006).

The above presentation of impact and value necessitates management questions, information and decisions. Boudreau and Ramstand (1998) argue that management information is used to support decisions, to persuade others and to set a fashion. D. Davis (2005) propounds specific information needs at strategic, tactical and technical (operational) levels, each associated with their own types of decision. The roles of the business and strategic partners (Ulrich, 1997) emphasise the integration between the HR function and the business to aid in decisions regarding the workforce. Consequently, this issue has certain implications for the measurement and management of employee-related data and information, as well as for employees, and thus needs some explication.

Similarly, a shift in the view regarding the source of value has impacted the conceptualisation and measurement of the workforce and the HR function. This shift includes the intangible people aspects, such as culture and employee engagement. In addition to transactional management of processes and best practices, an additional issue is the understanding of the economic value of people in human capital analytics. These developments have created a need to understand people as an asset, as will be highlighted next.

The changing context has created challenges for measurement frameworks. There is the necessity for an ongoing evaluation of HR practices, as there is no universal approach to improving organisational performance and it will thus vary between organisations (Bassi \& McMurrer, 2007; Brown, 2007). The purpose of this research was to answer the question: 'What are the domains to consider in managing and measuring people?' 'Domain' here refers to a territory under rule, control or influence (Domain, 2013). The concurrent research objective was to explore and describe changing management and measurement domains in the management of people amongst a selected panel of expert practitioners in human capital measurement. Linkage models that aim to express the contribution of people (human capital) to organisational performance were not considered.

Previous literature addressed various measurement frameworks that emerged over time to manage and measure the HR function and human capital. Historically, management predominantly made use of the Balanced Scorecard. This scorecard presents a limited understanding of the value and contribution of people, given the dynamic field of HR. Additional scorecards were developed to allow a more detailed approach to measuring the HR function (e.g. Becker et al., 2001) and the workforce (e.g. Huselid et al., 2005). The importance of employees in relation to organisational performance gained prominence in more recent analytic frameworks for example, the Human Capital Development Framework (Cantrell et al., 2006) and the Human Capital Capability Scorecard (Bassi \& McMurrer, 2008).

Aside from the research that informed the HR Scorecard and Workforce Scorecard (Becker et al., 2001; Huselid et al., 2005), little empirical work on recent domains to consider in managing and measuring performance exists. Previous work focused on the extension of existing domains (e.g. HR Scorecard and Workforce Scorecard), critique of existing frameworks (e.g. Wicks \& St. Clair, 2007) and the proposal of a new framework, namely the human capital bridge (Boudreau \& Ramstad, 2005). The main contribution of the present study was describing changing domains in the management and measurement of the HR function and human capital. The remainder of this article considers the theoretical framework that informed this research question, followed by the research design employed to explore and describe the question at hand. This is followed by the findings, after which a discussion and conclusion are presented.

\section{Literature review}

The measurement frameworks to be used internally within an organisation to manage and measure performance, with the business strategy as context, are discussed chronologically in this section. Three scorecards have been dominating people measurement, namely the Balanced Scorecard, the HR Scorecard and the Workforce Scorecard. Huselid et al. (2005) argue that these major scorecards share certain commonalities. Firstly, they integrate with Kaplan and Norton's (1996) Balanced Scorecard; secondly, strategy execution is emphasised (as opposed to operational issues) (Huselid et al., 2005); thirdly, they are based on a system of leading and lagging indicators and, finally, they include both tangible and intangible assets (Becker et al., 2001). The domains of each scorecard and inherent limitations are reviewed next.

\section{Balanced Scorecard}

Kaplan and Norton (1996) developed the Balanced Scorecard to assist management to clarify and translate the vision and strategy of an organisation, to communicate and link strategic objectives and measures, to plan, set targets and align strategic initiatives and to enhance feedback and learning. The Balanced Scorecard consists of four perspectives to measure. Financial themes, in the Financial Perspective, propel the business strategy. The Customer Perspective includes measurements of market share, customer retention, customer acquisition, customer satisfaction and customer profitability. In addition, it delineates the value proposition to customers, embedded in product and service attributes (functionality, quality and price), customer relationship (quality of purchasing experience and personal relationships) and image and 
reputation. The Internal Business Process Perspective centres around three processes, namely innovation, operations and post-sale service (Kaplan \& Norton, 1996). The impact of the HR function's strategies and practices are more prominent in the next perspective.

The Learning and Growth Perspective consists of two groups of measurements. The first group, core employee drivers, consists of satisfaction, retention and productivity. Satisfaction observes employee morale and overall job satisfaction. Retention focuses on retaining employees in whom the organisation has a long-term interest. Productivity measures reflect the sum of skills, morale, innovation, improved internal processes and satisfied customers (Kaplan \& Norton, 1996). Core employee drivers are influenced by situation-specific drivers, which are discussed next (Kaplan $\&$ Norton, 1996). The second group, situation-specific unique drivers, consists of staff competencies, climate for action and technological infrastructure. Staff competencies signify reskilling in terms of strategic skills, training levels and skills leverage. Climate for action refers to a key decision cycle, strategic focus, staff empowerment, personal alignment, morale and teaming. Technology infrastructure, which refers to strategic technologies, strategic databases, proprietary software and patents and copyrights, generates information about each customer's relationship with an organisation and rapid, timely and accurate feedback on products or services delivered to employees in operations (Kaplan \& Norton, 1996).

The design logic, to aid understanding of how value is created, centres around cause-and-effect relationships. The Learning and Growth Perspective (e.g. employee skills) drives the Internal Perspective (e.g. process quality and cycle time), which, in turn, impacts the Customer Perspective (e.g. on-time delivery and customer loyalty). These leading indicators ultimately drive a lagging indicator, namely the Financial Perspective (e.g. return on capital employed) (Kaplan \& Norton, 1996).

Three limitations exist, namely the integration of the HR function into the Balanced Scorecard and the underemphasis of the employee perspective, which is responsible for the concomitant management philosophy. The first limitation refers to a downsized representation of the HR function in the Internal Process Perspective (Boudreau \& Ramstad, 2002; Flamholtz, 2005). To address this limitation, Boudreau and Ramstand (2002) present alternative measures (such as calculating HR function financials, e.g. HR programme budgets, determining customers' levels of satisfaction using, e.g. HR client satisfaction surveys, determining operational efficiency, e.g. the yield rates of recruitment sources, and measuring learning and growth, e.g. the qualifications of HR practitioners) in all four perspectives. They argue that none of the approaches are indicative of a link to organisational outcomes. Brown (2007) also points to measurement complexities associated with organisational performance.
Brown (2007) expanded Kaplan and Norton's (1996) four perspectives to five categories. People metrics, for example, focuses on employee satisfaction, human capital, communication, health and safety, and diversity and ethics. Brown argues that the first three metrics are always important for all types of organisations. Human capital refers specifically to the value an employee has for an employer, as embedded in specific knowledge and skills, interpersonal knowledge and skills (non-technical abilities), intelligence or abilities and relationships. Possibly implied (but not made explicit) and related to employees in Brown's (2007) framework is the impact of external metrics, which consider variables such as brand image, external factors (e.g. local economy, employment and job growth) and risks (e.g. competitive threats, environmental risks, safety and security risks, research findings risks, legal risks and technological threats and risks). The measurement of HR productivity and processes is reflected in the operational metrics. The remaining two categories are (1) financial and strategic and (2) customer metrics (Brown, 2007). This approach perpetuates the limitation of the downsized HR function.

The second limitation points to the approximation of the learning and growth perspective to people (Flamholtz, 2005). Wicks and St. Clair (2007) point to the vagueness of the employees' perspective and argue that people are pulled towards an overall organisational vision (Kaplan \& Norton, 1992, cited in Wicks \& St. Clair, 2007) and, consequently, that motivation and commitment cannot be assumed. Though commitment is not addressed, Kaplan and Norton (2006) consider the notion of intrinsic and extrinsic motivation.

In reviewing the Learning and Growth Perspective, Kaplan and Norton (2004) shed light on the importance of intangible assets to support the internal processes. Three groups of intangible assets, termed strategic readiness, were identified: human capital (i.e. skills, training and knowledge), information capital (i.e. systems, databases and networks) and organisation capital (i.e. culture, leadership, alignment and teamwork). Two concepts in organisation capital deserve discussion. Kaplan and Norton (2004) describe leadership as motiving employees to new ways of working, specifically behaviours that support value creation (i.e. a focus on customers, innovation and results) and strategy execution (i.e. employees' understanding of the company's mission, vision and values, accountability, communications and teamwork). Culture encompasses culture as well as climate, reflected respectively in shared attitudes and beliefs free from the organisation's infrastructure and shared perceptions of formal and informal organisational policies and practices. Culture (and change) is critical, as it refers to new attitudes and behaviours required due to changes in the business strategy (Kaplan \& Norton, 2004). Kaplan and Norton argue that different stakeholders attach different levels of importance to intangible assets.

Despite Kaplan and Norton's (2004) move towards employee commitment, buttressed by culture, Wicks and St. Clair (2007) 
argue for the need for employee motivation (in this case, addressed by leadership) and a commitment philosophy, as there is no specific focus on employee commitment in the Balanced Scorecard and it is left to interpretation by management. Wicks and St. Clair propound the competing values framework to understand how culture and managerial behaviour impact organisational effectiveness. In addition to the Balanced Scorecard approach, emphasis is placed on collaboration (which focuses on improving employee satisfaction and work systems and enhancing employee learning) and creation (which refers to innovation, growth and promotion of health and wellness).

The third limitation articulates the philosophy management holds regarding measurement. Wicks and St. Clair (2007) point to the Balanced Scorecard's management philosophy, which focuses on control rather than commitment. A management philosophy marked by control presupposes a trade-off between the key variables of cost and quality and people, who may consequently be undervalued and overworked employees. This could result in negative quality and cost implications in the long run. Conversely, a commitment-based philosophy that fosters cooperation and trust allows organisations to respond more rapidly to changes in the environment (Khatri et al., 2006, cited in Wicks $\&$ St. Clair, 2007). In response, Wicks and St. Clair argue that their competing values framework is consistent with the commitment management philosophy. Rather than adapting particular HR-related and people-related limitations of the Balanced Scorecard, a new scorecard for HR, which is discussed next, was developed by Becker et al. (2001).

\section{Human Resource Scorecard}

Becker et al. (2001) developed the HR Scorecard to address the downsized HR function in the Balanced Scorecard. The HR Scorecard consists of five interrelated elements pertaining to the HR function. Competence refers to knowledge, skills, abilities or personality characteristics, and is represented in competencies such as knowledge of the business, delivery of HR practices, management of change, management of culture and personal credibility. High-performance work systems unique to each organisation are identified after defining the HR deliverables. High-performance work systems emphasise a performance focus of elements (e.g. HR policies, processes and practices) in the HR system (e.g. linking selection and promotion decisions to validated competency models, developing strategies to ensure skills demanded to execute strategy and enacting policies that attract, retain and motivate high-performing employees). System alignment refers to two dimensions of alignment, namely between strategy implementation and the HR system, and HR's strategic role and competencies of human resource practitioners and line managers; the two dimensions are linked to specific HR deliverables in executing the business strategy.

HR efficiency refers to core efficiency measures and strategic measures. HR deliverables consist of performance drivers and HR enablers. Performance drivers (which demonstrate strategic influence) relate to core people-related capabilities or assets (e.g. productivity and employee satisfaction). Since they are unique to organisations, it is challenging to identify them. HR enablers reinforce performance drivers and include an organisation's entire system of enablers or HR value chain (e.g. from employee selection to development and rewards).

This scorecard is underpinned by a specific design logic. Competencies effect a high-performance work system, which, in turn, impacts the system alignment and, as a consequence, ensures (or not) delivery and efficiency (Becker et al., 2001).

Similar to the Balanced Scorecard's limitation of underrepresentation of people, Beatty and Schneider (2005) point to a lack of prominence of employees and their strategic performance in the HR Scorecard. In addition, the role of line managers responsible for strategic performance of employees is understated in previous scorecards (Huselid et al., 2005). Huselid et al. (2005) addressed the limitation in employee representation and its critical role in strategy implementation, and subsequently developed the Workforce Scorecard, which is explicated next.

\section{Workforce Scorecard}

Huselid et al.'s (2005) Workforce Scorecard is a response to a missing link (i.e. people) between the Balanced Scorecard and the HR Scorecard. Their central argument rests on the notion that an effective workforce is, in addition to being the most important asset of an organisation, also critical to organisational performance and is controlled (directly and immediately) by managers.

Huselid et al. (2005) advocate four elements that are leading indicators of success, driving the implementation of operational, customer and financial strategies of the Balanced Scorecard. Workforce mindset and culture refer to the norms and expectations that the workforce needs to understand. Workforce competencies comprise the knowledge, skills and ability of each employee to execute the organisational strategy. Workforce behaviours consist of leadership and employee behaviours that are consistent with implementing the organisational strategy. The focus is on strategic employee performance rather than the contribution of the HR function (Huselid et al., 2005). Workforce success is:

\footnotetext{
the product of very specific leadership and workforce behaviours. Leadership and workforce behaviours are in turn a function of workforce competencies. Finally, competencies, behaviors, and results are a function of the firm's skills [ $p .70)$ and $]$ as such reflect how well the workforce has contributed to the execution of the organisation's strategy. (Huselid et al., 2005, p. 6)
}

The Workforce Scorecard integrates with the Balanced Scorecard and the HR Scorecard (see Huselid et al., 2005, for a visual depiction). To manage and measure workforce success, where the Workforce Scorecard bridges a gap 
between strategy and the HR function, is argued to be the optimal approach in value creation. This chain originates in an organisation's strategic and operational goals (embedded in the Balanced Scorecard), is cascaded into the development of a workforce strategy (in the Workforce Scorecard, with increasing responsibility of line management) and is subsequently reflected in the development of the HR function's strategy (in the HR Scorecard), which lays the foundation for the workforce being a strategic asset. Value is created in the opposite direction (from the Human Sciences Research Council [HSRC], through the Workforce Scorecard to the Balanced Scorecard) in this value chain.

Phillips (2005) published optional scorecards for human resource management on a smaller scale. These scorecards represent variations in configuration and focus; however, their focus is internal and transactional. Boudreau and Ramstand (2002) argue that scorecards focus on efficiency and effectiveness and lack an indicative link to organisational outcomes. In response, they developed the Human Capital Bridge to address this shortcoming (Boudreau \& Ramstad, 2007).

\section{Human Capital Bridge}

Boudreau and Ramstad (2007) retained the focus on efficiency and effectiveness. Efficiency is reflected in two elements, namely investments and policies and practices. Effectiveness underpins the elements of human capacity and aligned actions. The researchers added an impact anchor, which includes elements of talent pools and structures, resources and processes and, lastly, sustainable strategic success to address the shortcomings described above. Planning starts with the impact elements, then the effectiveness elements and, lastly, the efficiency elements. Execution happens in the opposite direction.

With the focus on impact, Xirogiannis, Chytas, Glykas and Valiris (2008) argue that, at strategic level (impact level), business strategy, organisational capabilities, HR practices, shareholder satisfaction, customer satisfaction and employee satisfaction (as an integrated domain) should be considered when designing a decision modelling tool to aid management in reasoning about strategic-level metrics.

It is evident that the HR function has shown increasing strategic functioning over time, considering various foci, outcomes, perspectives, the increasing importance of employees and logic. The changes are evident in the enlargement of focus (developments to address the limitations of scorecards over time), enlargement of outcomes (from efficiency to effectiveness to impact), the reflected enrichment of perspectives (e.g. health and safety, diversity and ethics, Brown, 2007), the importance of employees (e.g. in the Workforce Scorecard and the desired management philosophy, Wicks \& St. Clair, 2007) and lastly, a value-adding logic that connects various perspectives. What remains unchanged is the centrality of the business strategy.
The following section describes the research design employed to explore these issues.

\section{Research design Research approach}

This exploratory-descriptive (Marshall \& Rossman, 1999) investigation was embedded in the qualitative paradigm. Marshall and Rossman (1999) argue that exploratory studies furnish important categories of meaning that produce hypotheses for further investigation, owing to rich descriptions of underexplored complex circumstances, and descriptive studies aim to document and describe the phenomenon.

The researchers' ontology, the stance of reality and what can be known about it (Nel, 2007) are rooted in realism, which asserts an external reality independent of people's beliefs about it or understanding of it (Ritchie \& Lewis, 2004). Realists seek to understand a common reality in which people operate inter-dependently (Sobh \& Perry, 2006). Ontology favours a particular epistemology (Guba \& Lincoln, 1994), which considers what knowledge is, how it is possible, ideas about the natural world, how we can (and ought to) obtain knowledge, how we can (and ought to) reason and, consequently, refers to the methods, validity and scope of knowledge researchers use (Nel, 2007). The epistemological position was objectivism, which views phenomena as external facts outside the researcher's influence (Bryman \& Bell, 2003). Consequently, this study was approached with a distant, non-interactive posture and excluded values and other biases through empirical methods, including confounding factors, in order not to influence the outcomes, as recommended by Guba (1990).

\section{Case selection strategy}

For this investigation, a multiple case study approach was adopted to explore and describe the changing measurement domains. A case study strategy allows the exploration and description of a contemporary event (Mouton, 2001; Yin, 2009) without behavioural control of the events (Yin, 2009). Furthermore, it accommodates (exploratory-) descriptive questions and provides an understanding into the decisions participants take pertaining to a specific phenomenon (Yin, 2012). Moreover, to ensure depth and richness of the potential findings and analytical (transferability) as opposed to statistical generalisation, a multiple case study design was adopted. This design contributes to the credibility of an inquiry with multiple sources of evidence (e.g. field notes and observations and unsolicited secondary data) (Yin, 2012) and an a priori theoretical framework to guide data collection and analysis (Yin, 2009), all in a triangulation fashion that permits a convergence of data (Babbie \& Mouton, 2001; Yin, 2009) and thus enhances transferability (Babbie \& Mouton, 2001). The researchers in particular implemented Yin's (2012) holistic multiple case design, focussing on expert individuals. This design permits replication, given multiple cases (with a single unit of analysis), which allows assessment of findings 
(which could also include contrasting responses). Unsolicited documents (and field notes) were included in the analysis and treated as the voice of the participant; this ruled out Yin's embedded case study with multiple units of analysis and as such data was not treated as a separate unit of analysis.

\section{Research method}

\section{Research setting}

The field setting from which the data was sourced consisted of a small panel of expert practitioners (cases). These participants, who formed part of a group of measurement specialists, were actively involved in measurement; in particular, they exerted leadership and consulted at an executive level. The individuals were considered the unit of analysis.

\section{Entrée and establishing researcher roles}

Entrée was gained in two ways: firstly, by approaching an informant who participated and, thereafter, by contacting purposively selected participants (non-referred) known to the first and second author and snowballed participants (nominated). All participants were firstly contacted by phone to inquire about possible participation in this study. Nominated participants were informed of their nomination, without disclosing the identity of the referee. An informative email was then sent to the participant, detailing the purpose of this study. When continued interest was displayed, a convenient time was scheduled to conduct the interview.

\section{Sampling}

The researchers focused on a community of members who share a particular interest, in this case, the measurement of the HR function and people. In addition, they needed to be specialist practitioners who functioned at an executive level. Furthermore, these individuals needed to exert leadership and consult in the field of human capital measurement. This homogeneous approach was adopted to sample participants of similar background and experiences to understand a focused issue (Patton, 2002), as they may provide meaningful findings and interpretations (Guest, Bunce \& Johnson, 2006) and it may reduce the number of participants needed (Guest et al., 2006; Jette, Grover \& Keck, 2003).

The above criteria were applied to the non-probability sampling strategies as part of a systemic plan to avoid referral bias regarding nominees, which could result in friends or the easiest person to recruit being nominated (Davis, Johnson, Randolph, Liberty \& Eterno, 2005). Sampling commenced with a key informant (Babbie \& Mouton, 2001), who identified other possible participants. Snowball sampling was next applied, where collected data (Henning, Van Rensburg \& Smit, 2004), in addition to participant nomination (Brink, Van der Walt \& Van Rensburg, 2006), pointed to other possible participants. Purposive sampling, a third strategy, was employed, drawing on the researchers' knowledge about of the topic (Henning et al., 2004) and practitioners who were knowledgeable about the particular field (Brink et al., 2006).

Seven participants resulted from these sampling strategies. Six participants' data were included in the analysis; they were from the financial services industry (two cases), the information and communication technologies industry (three cases) and the food and beverages industry (one case). They occupied executive positions: two were in human resources, two were chief operating officers, one was involved in strategy and one in operations. Three participants were registered industrial psychologists and the remaining three had qualifications outside of the discipline of management. In addition, they all possessed a doctoral degree, except for one, whose highest qualification was a master's degree. They were all white men, aged between 41 and 57 years (the average age was 50). The data of a seventh participant (from the technology, i.e. software and computer services, sector) were excluded from the data analysis.

\section{Data collection methods}

Primary and secondary data was collected. To collect primary data, unstructured and open-ended interviews were employed to ensure intense and broad understanding of each individual's point of view. Participation and consent, in the context of confidentiality, were agreed upon at the beginning of an interview. Field notes were made during the interviews, with the permission of the participants. All participants were asked the same question, namely: 'What contextual factors should be taken into account in selecting human capital metrics?' Probing questions about core (Eriksson \& Kovalainen, 2008) and sensitising (Patton, 2002) concepts were posed in light of the immediate interview context (as facilitated by the field notes to formulate new questions, Patton, 2002) and the purpose of the study (Patton, 2002). Original interviews varied between $26 \mathrm{~min}$ and $1 \mathrm{~h} 23 \mathrm{~min}$. Unsolicited secondary data (e.g. participant-authored opinion articles and organisational documentation) were collected. This assisted in interpreting primary data by means of discussion, comment and debate (Mouton, 2001). Secondary data was analysed, with the consent of participants (Mason, 2002) and with the research question in mind.

\section{Recording of data}

Primary interview data was recorded at a high audio sampling rate to ensure clarity, which facilitated an efficient transcription process and, consequently, the verification of transcripts. Interviews were transcribed verbatim, including all superfluous phrases and words and other random aspects, such as interruptions and pauses. This approach provided confirmatory support during analysis for the rejection of one participant's data (see description below). Secondary data (i.e. solicited and unsolicited documents) and field notes were digitised where required. All data (primary and secondary) in paper format was converted and stored digitally (in Portable Document Format [PDF]) with password protection and backups in the digital domain. Digital data was also 
contextually stored as a hermeneutic unit in ATLAS.ti and protected by a password. Data in hard copy format was filed and locked away. The latter strategy facilitated the retrieval of data.

\section{Data analysis}

Schurink, Fouché and De Vos (2011) propound five important aspects of qualitative data analysis. Two particular aspects, namely that data analysis can be conducted in numerous ways and, hence, be classified into informal to formal strategies, informed the choice of data analysis method. An informal data analysis strategy, thematic analysis, as advocated by Braun and Clarke (2006), was employed to sort, systematise and analyse the data. Claims made using thematic analysis reflect reality in reporting patterns of experiences, meanings and the reality of the participants and thus do not develop a theory and are not wedded to a specific theory (Braun \& Clarke, 2006).

Braun and Clarke's (2006) approach to thematic analysis consists of six phases. Phase 1 commenced with data familiarisation, which focuses on the depth and breadth of data through repeated active reading in search of meanings and patterns. Field notes were used to assist with data familiarisation (Patton, 2002). Next, in Phase 2, initial code generation, data was organised into initial codes, as informed by interesting aspects that may form the basis of themes, through a systematic approach, with full and equal attention across the data set. Interviews were also coded for examples of measurements. In this phase, researchers choose between different approaches and levels of coding. Braun and Clarke propose an inductive (data-driven), deductive (theory-driven) or hybrid approach. An inductive approach was adopted and, in some cases, deductive, according to the research question, to formulate definitions of the codes at an explicit level. Both latent and semantic (in vivo code generation) levels were used. This is in agreement with Braun and Clarke's argument that analysis can focus exclusively or primarily on one level. Once data was related to codes, searching for themes (Phase 3) commenced. In this phase, different codes were sorted into potential themes. Relationships between codes, themes and different levels of themes were identified (Braun \& Clarke, 2006). Next, we validated themes against supporting data, in Phase 4: theme reviewing. Braun and Clarke claim that themes should 'adequately capture the contours of the coded data' (p. 91). Problematic themes may be collapsed into each other or broken down into separate themes; some themes may not be actual themes (e.g. if there is insufficient supporting data or the data is too diverse). Unstructured interviews result, as was experienced, in a great deal of time spent to code and find patterns in responses, due to different questions and resulting different responses (Patton, 2002). In Phase 5, defining and naming themes, we defined and further refined themes by considering the essence of each theme and the aspect of the data it captures and analysed data within the themes (Braun \& Clarke, 2006). The last phase, producing the report, entailed transferring output of Phase 5 in the format of a report (Braun \& Clarke, 2006).

\section{Strategies employed to ensure quality data}

The criteria for trustworthiness of qualitative research follow a mutually dependent logic, in that a study should be dependable (reliable) to be credible (valid) to be transferable (Lincoln \& Guba, 1985, cited in Babbie \& Mouton, 2001). Dependability refers to the notion of reaching similar findings when the same or similar participants are used in the same context when repeating a study (Babbie \& Mouton, 2001). Guba and Lincoln (1985, cited in Babbie \& Mouton, 2001) introduced the strategy of inquiry audit, in which an auditor examines 'critical incidents (documentation and interview notes) and a running account of the process of inquiry' (p. 278) and the product (Babbie \& Mouton, 2001). We documented the data reconstruction and synthesis illuminated by process notes, disseminated in this article, and a natural history and reflexivity in the original research report. This report also explicates the methodological and ethical complexities of this research design (Sugden \& Tomlinson, 1999, in Sparkes, 2002).

Credibility considers the truth as exemplified by the compatibility between the realities amongst participants and those that the researcher ascribes to them (Babbie \& Mouton, 2001). To ensure credibility, reflexivity was conducted (before and during the project), which contributed to objectivity, avoided bias brought about by background and prior knowledge (Taylor, Gibbs \& Lewins, 2005) and sensitised the researcher to the researcher-participant relationship and its consequences on data collection, analysis and representation (Mays \& Pope, 2000). In combatting bias, we applied selection criteria and specific sampling strategies. During data analysis, we conducted member checks, to review vague concepts and interpretation to deepen our understanding thereof (Patton, 2002). Peer debriefing was employed to review the process of coding and emerging themes, as well as to consider an outlier. Outliers may present valuable insights into the findings or, as a negative case, to expand and revise the interpretation to explain this outlier (Onwuegbuzie \& Leech, 2007). Consequently, Participant 1 was excluded from analysis, post theory and investigator triangulation (Denzin, 1978, in Seale, 1999). This case displayed conceptual confusion, exemplified by incorrect use of terminology. Additional intentional influencing tactics were also employed, namely social desirability (Babbie \& Mouton, 2001; Mouton, 2001) and impressions management (Roodt, 2009).

Data was collected to meet the criteria of adequacy, in particular, saturation, the attainment of which means that variation is understood and can be explained (Morse, 1994). Attaining breadth and depth (Bowen, 2008) and a concern for meaning and not frequencies (Mason, 2010) guided the data analysis to achieve saturation. During Phase 2 of Braun and Clarke's (2006) thematic analysis, transcripts 
were coded to achieve breadth and saturation of codes was reached after the first five participants' interviews were coded, after which no new codes emerged. Saturation is reached when no new codes emerge, as argued by Guest et al. (2006). In order to account for more detail and variation as propounded by Charmaz (2006), the focus shifted to a depth of saturation at which point codes were sorted into themes (Phase 3) and selected themes were collapsed into each other (Phase 4) to reveal the domains discussed in the findings. In addition, a natural history that explicated methodological and ethical complexities of this research design (Sugden \& Tomlinson, 1999 in Sparkes, 2002) accompanied the original research project.

Transferability is the extent to which findings can be related to other participants (or contexts) and necessitates credibility (Babbie \& Mouton, 2001). Sufficiently detailed descriptions (thick descriptions) of contextualised data were collected and reported (Babbie \& Mouton, 2001). Purposive sampling maximised the range of information from and about the context (Babbie \& Mouton, 2001). In addition, snowball sampling was employed to locate specialists to maximise information (Babbie \& Mouton, 2001).

Confirmability was approximated through investigator and theory triangulation, an audit trail and inter-rater reliability: the coding process outcomes were verified by two peer investigators not part of this study.

\section{Reporting}

A scientific style, an external privileged researcher's account (Sparkes, 2002), is employed to report what has been found (Plummer, 2001, in Sparkes, 2002). In support of the merit and validity of the analysis (Braun \& Clarke, 2006), a realist writing style (Sparkes, 2002) was employed to foreground participants' voices and was embedded within the analytical narrative (or scientific writing style, Braun \& Clarke, 2006). Selected participants' quotations were edited, since English was not the first language of most participants, by removing unnecessary repetitions or patterns of words and irrelevant or disjointed interjections; '[sic]' was added to anomalous or erroneous sections.

\section{Findings}

Seven domains to measure were found. Groundedness of the domains (themes) across the dataset is indicated in brackets.

\section{Domain 1: Burning issues and emerging trends within the people arena (7)}

Participant 4 explained that organisations, in a turbulent context, must be able to scan the external environment to be informed about people challenges, trends and issues:

'That's the storm the pilot is flying into. [This domain becomes the] radar screen, so to speak, [showing] what the weather patterns or systems look like.' (Participant 4, male, 57)
Participant 4 offered qualitative benchmarking to understand nuances within the organisation and leading practices and world-class people management employed by organisations:

'You can do the quantitative assessments, but you miss out a lot in the nuances.' (Participant 4, male, 57)

'You may be doing reasonably well on the figures but qualitatively are you a world class? Do you have world-class people management in your company?' (Participant 4, male, 57)

There are general issues and trends to keep track of, for example talent management and employment equity (as a strategic issue):

'The main one is your environmental scanning domain where you say, "What are the burning issues and emerging trends with respect to the people arena?" In other words what are the things? EE [employment equity], ah talent management, that tells you these are the things you have to watch.' (Participant 4, male, 57)

\section{Domain 2: Human resource function delivery excellence (35)}

This domain considers the functioning of two elements, namely the HR function (and practices) and HR professionals, alongside the HR value chain. Participant 4 described the domain as follows:

'This is your performance along your HR value chain ... [also] your HR value chain delivery ... [where you look] at the HR function itself ... [and the] service delivery excellence by the people [HR] professionals.' (Participant 4, male, 57)

In addition to compliance, the HR function needs to have effective practices that could predict an impact on the organisation:

'So, in other words, if you've done all your good HR, like your training and your good pipeline management and equity management and all of those sorts of things, they could predict a hard-nose $[d]$ business sales performance a year later in a team which is pretty good.' (Participant 7, male, 54)

However, the HR practices facilitated by HR professionals are inseparable and, once optimised, may contribute to the success of the various functions:

'One of the other things that we do is that we have an HR review which is an annual review of all the HR functions within the business. And, you know, again it's driven by hard-nose[d] metrics that we collect all the stuff in, have a look [at] it and say, "Look, you know, if you're a good HR team, you're helping your business unit to slow down labour turnover. You're helping your business unit speed up filling of vacancies. You help your business unit attract high calibre talent." And through all of those processes, by optimising your workforce, sales, marketing, manufacturing and all the rest of the line functions, ... [you contribute to them [business units].' (Participant 7, male, 54)

Examples of measurements found are: the HR budget (allocation and compliance), HR expenses (e.g. spend on recruitment, spend on and cycle time of the process), quality and utilisation (e.g. with competency acquisition and implementation), return on investment, revenue (e.g. 
HR costs relative to total revenue of the organisation) HR practitioners versus full-time equivalents and span of control.

\section{Domain 3: Strategic people initiatives' progress (7)}

The purpose of this domain is to track strategic people initiatives 'like a little bit of a project' (Participant 4):

'[These are] strategic people issues and how you are progressing against that and what value they are already adding to the business.' (Participant 4, male, 57)

'Let's say you're introducing leadership development in your company. And only installing or putting in a learning academy and putting your leaders through that, how far are [we] with it?' (Participant 4, male, 57)

Failing to focus on strategic people initiatives may cause the organisation to suffer, as Participant 1 explained:

'But the overall direction of the business suffer, because I ... haven't elevated the business.' (Participant 1, male, 54)

Measurement should be included in the management of these initiatives or projects:

'It says also [that] we expect now, through our leadership development, à la Phillips or Kirkpatrick, to see a 5\% difference in the effectiveness of our leaders.' (Participant 4, male, 57)

Talent management was indicated as a concept to consider. Other, limited examples refer to the unique strategic contexts of organisations.

\section{Domain 4: Employee contribution to business success (42)}

Some participants claimed the importance of the contribution of employees to the performance and success of business performance indicators in the context of the business strategy:

'How are people contributing to the success of the business in terms of the key performance indicators for the business. Of course those indicators ... have to then also be contextualised and will be determined by the strategy of the business.' (Participant 4, male, 57)

Participant 4 mentioned that this domain represents the perspectives of the Balanced Scorecard, excluding the Learning and Growth Perspective:

'And your business Balanced Scorecard actually sits inside that block. In other words, how much profit are you generating per employee, how are you growing your market share per employee that you employed, across [three] dimensions of the Balanced Scorecard.' (Participant 4, male, 57)

Participant 5 indicated that people-related measures should be linked to performance indicators, which also assist to formulate a business strategy:

'Think about how you as HR help this business to compete better ... all the metrics that you use help this business to grow market share, to make more money, to sell more merchandise. ... So once the dependent variable for HR practitioners can be whatever the purpose of business of that particular business is, then I think we'll get this sorted. So on our retail side it's about selling furniture. Right. So the HR metric must be within that context.' (Participant 5, male, 48)

Dependent variables found, though non-exhaustive, were, for example: profit, growth, market share, innovation, sustainability and operational excellence.

\section{Domain 5: The effectiveness of the human resource value chain (135)}

This domain focuses on the effectiveness of the HR value chain in supporting the business value chain within an organisational context (i.e. design of the organisation and related processes). Participants advocated the efficiency and effectiveness of activities and processes in the HR value chain, as embedded in the understanding of the specific roles and responsibilities. Participant 2 explained the importance of understanding the context:

'It's about understanding where it $[H R]$ fits into the [business] value chain, ... what's the role, what are the key activities that are performed by this particular environment ... what is that they're [HR function] trying to achieve in the organisation?' (Participant 2, male, 51)

Three elements contribute to the effectiveness of the HR value chain. Firstly, cascading the business strategy and understanding the implementation thereof in the business value chain:

'Then you start to disaggregate them, pull that down and say, "Which part of this organisation is responsible for doing that?"' (Participant 2, male, 51)

'Implementation once you [HR strategic partner] have decided what the strategy is and [have] tested it with these guys [management of functions] and said, "That's it. That's possible." But that how to think, how to position, who's positioned where, how are we going to manage the dynamics, all of those sort of things which are sort of somewhere between tactics and strategy, I suppose, I think the HR guys do play a very significant role, or can.' (Participant 2, male, 51)

Secondly, a solid understanding of the activities (including inputs and outputs) in the business value chain will influence the enabling people policies and practices:

'What are the inputs? What are the outputs? What do I want and how am I going to drive behaviour that is consistent with where I want to get the business strategically?' (Participant 2, male, 51)

'Then you have to look at your enabling people policies and practises. Out of that you will define your modes of client engagement with the company and then you would have to define the people contribution to the success of these organisations.' (Participant 4, male, 57)

Lastly, a partnership with the business ensures a supporting HR value chain:

'You can't be a partner unless you have a shared desired outcome. And, taking it to the metrics level, if you are HR and you are measured on staff turnover, for example, you can't be a partner to me unless I am also measured to some extent on staff 
turnover and you are also measured, at least part, by what I'm responsible for.' (Participant 3, male, 47)

' $[W e]$ can only get this right if we close the loops. Here's [sic] the HR experts. Here's [sic] the support functions in business. Here's the front end of business, we sell stuff. We're here to compete better. Let's get these links sorted.' (Participant 5, male, 48)

Groups of representing measurements found amongst the participants were: staffing (recruitment and selection, headcount and turnover), competence acquisition, performance of talent (differentiation of the workforce), succession planning, employment relations and compliance (e.g. employment equity).

\section{Domain 6: Employee engagement (33)}

Participant 4 described this domain, found amongst most of the participants, as follows:

'It deals with the compelling reasons [or measures] why this desired, ideal person(s) must join and stay with the organisation [and] aims to maximise people's engagement in the organisation in terms of their hearts, minds and spirit.' (Participant 4, male, 57)

Participant 7 gave an example of causation between Domain 5 (HR value chain effectiveness) and how it impacts this domain:

'I did [a] study a couple of years ago, looking at the correlations between $[a]$ whole host of HR variables, organisational climate and hard-nosed business measures. And I found that not only were the correlations between them significant in a crosssectional setting, they are also predictable over a one year period.' (Participant 7, male, 54)

Examples mentioned by participants of what to consider to measure were: employer-employee value proposition, organisational culture and climate, employee commitment, motivation, morale, health (relating to stress), characteristics of a job (e.g. interesting and exciting, stretched goals and accountability), employee satisfaction, communication and feedback.

\section{Domain 7: Customer satisfaction (32)}

Some participants indicated the importance of customer satisfaction, both externally and internally. Although usually associated with external customer satisfaction, some participants made reference to Sears and Roebuck and Co.'s employee-customer-profit chain, in which employees, customers and profit are causally related (as discussed in Becker et al., 2001). Participant 4 included leadership in the above causal chain as impacting on peoples' attitudes and, ultimately, (internal) customer satisfaction:

'Here's my leadership. This is what leadership does. It impacts on my people and particularly their attitudes. Attitudes in turn affect customer satisfaction, customer satisfaction in turn affect the profitability of the company.' (Participant 4, male, 57)

'When you integrate with your other functions in terms of customer satisfaction that will, with high levels of motivation, impact your bottom line positively. We make those assumptions.' (Participant 7, male, 54)
Two participants pointed to challenges of the above assumption, both pointing to validity issues:

'It's not necessarily true because if there's competitive product on the market that comes in at a same quality, significantly lower price or whatever, the customer may still be very happy with you.' (Participant 2, male, 51)

'But it's amazing how many different versions there are of what constitutes customer satisfaction or sales performance. You'd think it's quite simple, but the more you think ... the more you uncover dangerous assumptions.' (Participant 3, male, 47)

The implementation of the business strategy within the business and HR value chain (see Domain 5) will ultimately shape and influence customer expectations and satisfaction:

'So you'll have to go and contextualise it. Look at some of these general things because you'll have to educate your customer and then relate and say, "Okay, this one could be important for you in relation to that because you are a factory and you've got a mine."' (Participant 6, male, 41)

All participants referred, unqualified though, to customer satisfaction to measure. Only Participant 4 highlighted the number of customer complaints per thousand employees as a measurement.

\section{Discussion}

The purpose of this study was to explore and describe changing domains in human capital measurement. Consequently, this study highlighted seven domains, especially the emerging focus on intangibles (employee engagement and customer satisfaction), as being important to measure. The main contribution of this study is to describe changing domains in the management and measurement of the HR function and human capital.

Four new domains were found, namely Domains 1, 3, 6 and 7. Domain 1 has not previously been discussed in the literature and senior management in HR is urged to scan the external environment. Domain 3, in which strategic people initiatives are monitored, is a new configuration, despite literature that propounds the use of scorecards to implement a strategy (i.e. people initiatives) (Becker et al., 2001; Huselid et al., 2005; Kaplan \& Norton, 1996). Domain 7 escalates the importance of leadership in strategy implementation to a separate domain. Literature partially addresses aspects of leadership and climate (Kaplan \& Norton, 2004), motivation and a management philosophy of commitment (Wicks \& St. Clair, 2007). A possible explanation for the new configuration of domains may be a systems approach for the HR function and human resource practitioners, to be integrated and influenced organisation-wide. Domain 1 could be explained by the increasing importance of strategy formulation and implementation for HR professionals.

Domains 2, 4 and 5 reflect previous scorecards. The HR Scorecard's (Becker et al., 2001) doables and deliverables are reflected in Domain 2 (i.e. HR competencies and practices and HR costs) and Domain 5 (i.e. HR system alignment). 
The Workforce Scorecard (Huselid et al., 2005) is reflected in Domains 6 and 7 (i.e. leadership and workforce behaviours), as well as Domain 3 (i.e. workforce success against strategic objectives). Of note is the scant representation of the workforce's mindset and culture (as found in Domains 2, 4 and 6) and competencies in a particular domain. The Financial Perspective of the Balanced Scorecard (Kaplan \& Norton, 1996) is reflected in Domain 4.

The domains reflect new areas of impact and level of management. Domains 1 to 3 focus on the HR function and senior management, with Domain 2 also calling for a monitoring (transactional) role. In partnership with line management, Domains 4 and 5 focus on the organisation (external to the HR function) and respectively call for a strategic and a transactional role. Similarly, Domains 6 and 7 focus on both the HR function and the organisation; each calls for a strategic and a transactional role. Perspectives that are impacted in a logical sequence in scorecards (Becker et al., 2001; Huselid et al., 2005; Kaplan \& Norton, 1996) gave way to considering what and who is to be impacted and implied and the level of management required to do so. A possible explanation could be a systemic approach to the organisation (and not perspectives of value-add).

Given the focus of impact, discussed above, it is no surprise to find the concept of understanding contribution and value that is now embedded in finding relationships across domains. Despite scorecard literature advocating perspectives that, through a sequence of leading perspectives, create value and measure relationships (Becker et al., 2001; Huselid et al., 2005; Kaplan \& Norton, 1996), participants' focus shifted to systemically understand value in terms of relationships.

The above focus on cross-domain relationships now allows for understanding and creating impact, both within the HR function (internal focus) and outside of the HR function (external focus). Impact has been understood in terms of scorecard perspectives (which include efficiency and effective measures) (Becker et al., 2001; Huselid et al., 2005; Kaplan \& Norton, 1996), in agreement with Boudreau and Ramstad (2007), who argue for impact within the HR function with regard to certain elements.

In conclusion, the HR function and workforce remain important and particular attributes to consider have been regrouped within an internal or external focus of the HR function. Furthermore, changing roles (not necessarily competencies) are noticeable within the architecture and modes of engagement within the HR function. This then points to the importance of the conceptualisation of the HR function according to a systems approach and how to unravel the value embedded in the workforce. Furthermore, the leading indicator perspectives of the scorecard parlance gave way to an understanding of relationships amongst domains and how to create an impact on these relationships. As such, strategy formulation can no longer rely on scorecard perspectives. Complexity in relationships now drives strategy formulation and implementation.

\section{Practical implications}

This study has implications for various stakeholders. For HR practitioners, reconceptualised domains (architecture) of performance to manage and measure, including new HR programmes and practices like ethics and diversity, are made available. In addition, these domains separate the HR function into different levels (strategic and operational) and areas of responsibility to allow human resource practitioners to function at a particular level of complexity. Consequently, these domains compel HR professionals to move beyond a performance management paradigm into a strategic paradigm to allow for an understanding of possible change inside and outside the organisation that may influence the formulation of the business strategy. Thus, the implementation process of the strategy becomes a transactional activity that now focuses attention on the formulation of business strategy or strategic change. Such differentiation allows for specific types and levels of information, tailor-made for specific audiences within and outside the HR function. The domains found allow line managers not only to take decisions, but also to monitor specific aspects within these domains that are of importance to their function. The above necessitates higher education institutions to focus on the development of students' cognitive skills to allow systems thinking and functioning within a complex environment.

\section{Limitations of the study}

Despite efforts to ensure dependability and transferability, the findings are limited to a particular context, as the research design was directly applicable to the research participants (or six multiple cases) investigated in specific sectors in the South African context. Despite the limitations, this type of study provides an in-depth description of a small number of cases, which ensures high construct validity and in-depth insights into the findings (Mouton, 2001).

\section{Suggestions for future research}

The reconceptualisation of the roles within the HR function should be quantitatively explored and explained. Furthermore, a similar exercise should consider the levels of complexity and responsibility and how they relate to the development of the business strategy.

\section{Conclusion}

The purpose of this study was to identify changing measurement domains in human capital management. Taking a qualitative approach and applying thematic analysis to the unstructured interview data of six expert practitioners functioning at executive level, seven domains were found. Therefore this study has met its objective.

\section{Acknowledgements}

We thank the two anonymous reviewers for their helpful comments. Prof Willem Schurink is acknowledged for his contributions to the methodology of this study. 


\section{Competing interests}

The authors declare that they have no financial or personal relationship(s) that may have inappropriately influenced them in writing this article.

\section{Authors' contributions}

P.D.C.-F. (University of Johannesburg) and G.R. (University of Johannesburg) were responsible for the overall conceptualisation of this study, whilst the first author executed the study and wrote the article.

\section{References}

Babbie, E., \& Mouton, J. (2001). The practice of social research. Cape Town South Africa: Oxford University Press Southern Africa (Pty) Ltd.

Bassi, L.J., \& McMurrer, D.P. (2006). Beyond employee satisfaction, ROI, and the Balanced Scorecard: Improving business results through improved human capital measurement. In R.C. Preziosi (Ed.), The 2006 Pfeiffer Annual: Human Resource Management, (pp. 3-15). San Francisco, CA: John Wiley \& Sons, Inc.

Bassi, L.J., \& McMurrer, D.P. (2007). Maximizing your return on people. Harvard Business Review, 85(3), 115-123.

Bassi, L.J., \& McMurrer, D.P. (2008). Toward a human capital measurement methodology. Advances in Developing Human Resources, 10(6), 863-881. http:// dx.doi.org/10.1177/1523422308325611

Beatty, R.W., \& Schneider, C.E. (2005). Workforce strategy: A missing link in HR's future success. In M. Losey, S. Meisinger \& D. Ulrich (Eds.), The future of human resource management: 64 Thought leaders explore the critical HR issues of today and tomorrow, (pp. 199-207). Hoboken, NJ: John Wiley \& Sons, Inc.

Becker, B., Huselid, M.A., \& Ulrich, D. (2001). The HR Scorecard: Linking people, strategy, and performance. Boston, MA: Harvard Business School Press.

Boudreau, J.W., \& Ramstad, P.M. (1998). Human resource metrics: Can measures be strategic? CAHRS working paper \#98-10. Ithaca, NY: Cornell University, School of Industrial and Labor Relations, Center for Advanced Human Resource Studies.

Boudreau, J.W., \& Ramstad, P.M. (2002). Strategic HRM measurement in the 21st century: From justifying HR to strategic talent leadership. CAHRS working pape \#02-15. Ithaca, NY: Cornell University, School of Industrial and Labor Relations, Center for Advanced Human Resource Studies.

Boudreau, J.W., \& Ramstad, P.M. (2005). Talentship, talent segmentation, and sustainability: A new HR decision science paradigm for a new strategy definition. Human Resource Management, 44(2), 129-136. http://dx.doi.org/10.1002/ hrm.20054

Boudreau, J.W., \& Ramstad, P.M. (2007). Beyond HR: The new science of human capital. Boston, MA: Harvard Business School Press.

Bowen, G. (2008). Naturalistic inquiry and the saturation concept: A research note Qualitative Research, 8(1), 137-142. http://dx.doi.org/10.1177/1468794107085301

Braun, V., \& Clarke, V. (2006). Using thematic analysis in psychology. Qualitative Research in Psychology, 3(2), 77-101. http://dx.doi.org/10.1191/1478088706qp063oa

Brink, H., Van der Walt, C., \& Van Rensburg, G. (2006). Fundamentals of research methodology for health care professionals. Cape Town, South Africa: JUTA \& Co.

Brown, M.G. (2007). Beyond the Balanced Scorecard: Improving business intelligence with analytics. New York, NY: Productivity Press.

Bryman, A., \& Bell, E. (2003). Business research methods. Oxford, UK: Oxford University Press.

Cantrell, S., Benton, J.M., Laudal, T., \& Thomas, R.J. (2006). Measuring the value of human capital investments: The SAP case. Strategy and Leadership, 34(2), 43-52. $\mathrm{http} / / / \mathrm{dx}$.doi.org/10.1108/10878570610652626

Charmaz, K. (2006). Constructing grounded theory: A practical guide through qualitative analysis. Thousand Oaks, CA: SAGE Publications Ltd.

Davis, D. (2005). Business research for decision making. Belmont, CA: Thomson Brooks/ Cole.

Davis, W.R., Johnson, B.D., Randolph, D., Liberty, H.J., \& Eterno, J. (2005). Comparing police drug allegations with enumerations of drug users/sellers. An Internationa Journal of Police Strategies and Management, 28(4), 594-608. http://dx.doi. org/10.1108/13639510510628686

Domain. (2013). In Oxford English Dictionary. Oxford University Press.

Eriksson, P., \& Kovalainen, A. (2008). Qualitative methods in business research. Los Angeles, CA: SAGE Publications, Inc. http://dx.doi.org/10.4135/9780857028044

Flamholtz, E.G. (2005). Human resource accounting: Human capital management, and the bottom line. In M. Losey, S. Meisinger \& D. Ulrich (Eds.), The future of human resource management: 64 Thought leaders explore the critical HR issues of today and tomorrow, (pp. 268-277). Hoboken, NJ: John Wiley \& Sons, Inc.

Guba, E.G. (1990). The alternative paradigm dialog. In E.G. Guba (Ed.), The paradigm dialog, (pp. 17-27). Newbury Park, CA: SAGE Publications, Inc.

Guba, E.G., \& Lincoln, Y.S. (1994). Competing paradigms in qualitative research. In N.K. Denzin \& Y.S. Lincoln (Eds.), Handbook of qualitative research, (pp. 105-117). Thousand Oaks, CA: SAGE Publications, Inc.
Guest, G., Bunce, A., \& Johnson, L. (2006). How many interviews are enough? An experiment with data saturation and variability. Field Methods, 18(1), 59-82. http://dx.doi.org/10.1177/1525822X05279903

Henning, E., Van Rensburg, W., \& Smit, B. (2004). Finding your way in qualitative research. Pretoria, South Africa: Van Schaik Publishers.

Huselid, M.A., Becker, B., \& Beatty, R.W. (2005). The Workforce Scorecard. Boston, MA Harvard Business School Press.

Jette, D.J., Grover, L., \& Keck, C.P. (2003). A qualitative study of clinical decision making in recommending discharge placement from the acute care setting. Physical Therapy, 83(3), 224-236.

Kaplan, R.S., \& Norton, D.P. (1996). The Balanced Scorecard: Translating strategy into action. Boston, MA: Harvard Business School Press.

Kaplan, R.S., \& Norton, D.P. (2004). Measuring the strategic readiness of intangible assets. Harvard Business Review, 82(2), 52-63.

Kaplan, R.S., \& Norton, D.P. (2006). Alignment: Using the Balanced Scorecard to create corporate synergies. Boston, MA: Harvard Business School Publishing Coorporation

Marshall, C., \& Rossman, G.B. (1999). Designing qualitative research. (3rd edn.). Thousand Oaks, CA: SAGE Publications, Inc.

Mason, J. (2002). Qualitative researching. (2nd edn.). Thousand Oaks, CA: SAGE Publications, Inc.

Mason, M. (2010). Sample size and saturation in PhD studies using qualitative interviews. Forum Qualitative Sozialforschung/Forum: Qualitative Socia Research, 11(3). Retrieved April 11, 2014, from http://www.qualitative-research. net/index.php/fqs/article/view/1428/3027

Mays, N., \& Pope, C. (2000). Qualitative research in health care: Assessing quality in qualitative research. British Medical Journal, 320(50), 50-52. http://dx.doi. org $/ 10.1136 / \mathrm{bmj} .320 .7226 .50$

Morse, J.M. (1994). Designing funded qualitative research. In N.K. Denzin \& Y.S Lincoln (Eds.), Handbook of qualitative research, (pp. 220-235). Thousand Oaks, CA: SAGE Publications, Inc.

Mouton, J. (2001). How to succeed in your master's and doctoral studies: A South African guide and resource book. Pretoria, South Africa: Van Schaik Publishers.

$\mathrm{Nel}$, J.P. (2007). Epistemology vs ontology. Retrieved September 13, 2010, from http:// www.mentornet.co.za/files/documents/epistemologyvsontology.pdf

Onwuegbuzie, A.J., \& Leech, N.L. (2007). Validity and qualitative research: An oxymoron? Quality \& Quantity, 41, 233-249. http://dx.doi.org/10.1007/s11135 006-9000-3

Patton, M.Q. (2002). Qualitative research and evaluation methods. (4th edn.) Thousand Oaks, CA: SAGE Publications, Inc.

Phillips, J.J. (2005). Investing in your company's human capital: Strategies to avoid spending too little-or too much. New York, NY: American Management Association.

Ritchie, J., \& Lewis, J. (2004). Qualitative research practice: A guide for social science students and researchers. London, UK: SAGE Publications, Inc.

Roodt, G. (2009). Power and politics. In S.P. Robbins, T.A. Judge, A. Odendaal \& G. Roodt (Eds.), Organisational behaviour: Global and South African perspectives, (2nd edn.) (pp. 349-373). Cape Town, South Africa: Pearson Education South Africa.

Scholz, C., Stein, V., \& Müller, S. (2007). Monetary human capital measurement Empirical evidence from the German DAX 30 companies. Paper presented at the annual meeting of the Academy of Management, Philadelphia, PA, 03-08 August.

Schurink, W.J., Fouché, C.B., \& De Vos, A.S. (2011). Qualitative data analysis and interpretation. In A.S. de Vos, H. Strydom, C.B. Fouché \& C.S.L. Delport (Eds.), Research at grass roots for the social sciences and human service professions, (4th edn.) (pp. 397-423). Pretoria, South Africa: Van Schaik Publishers.

Seale, C. (1999). The quality of qualitative research. Thousand Oaks, CA: SAGE Publications, Inc

Sobh, R., \& Perry, C. (2006). Research design and data analysis in realism research. European Journal of Marketing, 40(11/12), 1194-1209. http://dx.doi. org/10.1108/03090560610702777

Sparkes, A.C. (2002). Telling tales in sport and physical activity: A qualitative journey. Champaign, IL: Human Kinetics.

Taylor, C., Gibbs, G.R., \& Lewins, A. (2005). Quality of qualitative analysis. Retrieved September 13, 2010, from http://onlineqda.hud.ac.uk/Intro_QDA/qualitative analysis.php

Ulrich, D. (1997). Human resource champions: The next agenda for adding value and delivering results. Boston, MA: Harvard Business School Press.

Wicks, A.M., \& St. Clair, L. (2007). Competing values in healthcare: Balancing the (un) Balanced Scorecard. Journal of Healthcare Management, 52(5), 309-324.

Xirogiannis, G., Chytas, P., Glykas, M., \& Valiris, G. (2008). Intelligent impact assessment of HRM to the shareholder value. Expert Systems with Applications, 35(4), 2017-2031. http://dx.doi.org/10.1016/j.eswa.2007.08.103

Yin, R.K. (2009). Case study research: Design and methods. (4th edn.). Thousand Oaks, CA: SAGE Publications, Inc.

Yin, R.K. (2012). Applications of case study research. (3rd edn.). Thousand Oaks, CA: SAGE Publications, Inc 